\title{
Postural tachycardia syndrome: current perspectives
}

This article was published in the following Dove Press journal: Vascular Health and Risk Management

\author{
Rachel Wells ${ }^{1,2}$ \\ Andrew J Spurrier ${ }^{3}$ \\ Dominik Linz' \\ Celine Gallagher' \\ Rajiv Mahajan' \\ Prashanthan Sanders' \\ Amanda Page ${ }^{4}$ \\ Dennis H Lau' \\ 'Centre for Heart Rhythm Disorders, \\ South Australian Health and Medical \\ Research Institute, University of \\ Adelaide and Departments of \\ Cardiology and Medicine, Royal \\ Adelaide Hospital, ${ }^{2}$ Department of \\ Medicine, Royal Adelaide Hospital, \\ ${ }^{3}$ Sound Radiology, ${ }^{4}$ Centre for \\ Nutrition and Gastrointestinal \\ Diseases, University of Adelaide, \\ Adelaide, SA, Australia
}

\begin{abstract}
Postural tachycardia syndrome (POTS) is the combination of an exaggerated heart rate response to standing, in association with symptoms of lightheadedness or pre-syncope that improve when recumbent. The condition is often associated with fatigue and brain fog, resulting in significant disruptions at a critical time of diagnosis in adolescence and young adulthood. The heterogeneity of the underlying pathophysiology and the variable response to therapeutic interventions make management of this condition challenging for both patients and physicians alike. Here, we aim to review the factors and mechanisms that may contribute to the symptoms and signs of POTS and to present our perspectives on the clinical approach toward the diagnosis and management of this complex syndrome.
\end{abstract}

Keywords: orthostatic, autonomic, hypermobility, baroreflex, doppler

\section{Introduction}

Postural tachycardia syndrome (POTS) is a chronic debilitating condition characterized by symptoms of lightheadedness, fatigue, palpitations, pre-syncope, sleep disturbances, cognitive impairment and brain fog in conjunction with an exaggerated increase in heart rate (HR) when upright, despite maintenance of a normal blood pressure. ${ }^{1}$ The exaggerated HR response is defined as a sustained increment $>30$ beats per minute (bpm) in adults, or $>40 \mathrm{bpm}$ in children, that occurs within 10 minutes of standing. The nonspecific nature of symptoms, bell curve of HR responses to orthostasis in the general population and a lack of specific biomarkers have made it difficult to establish the true prevalence of POTS. The onset of POTS symptoms may be gradual and can be triggered by an infective illness. There is a higher than expected prevalence of joint hypermobility and chronic fatigue syndrome in patients with POTS. It occurs more commonly in adolescent females, but is rare in patients over the age of 40 years.

The pathophysiology underlying POTS remains incompletely understood, is likely to be multifactorial and varies in different subgroups of POTS patients. Factors such as moderate autonomic dysfunction, increased sympathetic tone, severe deconditioning, inadequate venous return or excessive blood venous pooling may contribute to POTS symptoms. ${ }^{2}$ Poor venous return may be a result of impaired vasoconstriction secondary to a number of factors and concurrent clinical syndromes. Autoimmunity and mast cell activation syndromes have been postulated as contributing to the development of POTS in some patients, but immunotherapy is rarely indicated and the relevance of autoantibodies and mast cells in most patients with POTS remains controversial. ${ }^{3-5}$ Due to the complexity and heterogeneity in the presentation of this syndrome, POTS patients are often subjected
Department of Cardiology, Centre for Heart Rhythm Disorders (CHRD), Royal Adelaide Hospital, Adelaide, SA 5000, Australia

Tel +6I 882222723

Fax +6I 882222722

Email dennis.h.lau@adelaide.edu.au 
to extensive and unnecessary investigations, with fragmented care provided by multiple specialists. Available therapies for this condition are limited and directed toward symptom control by either increasing intravascular volume, increasing peripheral vascular tone or controlling HR. The response to therapeutic interventions is highly variable, with improvement in HR control not always improving the quality of life, rendering management of this condition highly challenging. Until now, robust data on POTS therapies from well-conducted trials are lacking, with many options based on anecdotal evidence alone. ${ }^{6}$

Here, we aim to first review the association between POTS and several other clinical syndromes. Next, we discuss the clinical approach regarding history taking, physical examination, use of symptom questionnaires and targeted investigations. Finally, we aim to summarize the management (both nonpharmacologic and pharmacologic) approaches in treating this complex syndrome.

\section{Concurrent clinical syndromes} Irritable bowel syndrome (IBS)

Symptoms of IBS, food intolerance and allergic sinusitis, are commonly reported in individuals with POTS. ${ }^{7}$ Although rarely performed, plethysmography may demonstrate splanchnic venous pooling in patients with IBS. ${ }^{8}$ The baroreflex response to reduced venous return (consequent to histamine or localized small molecule related vasodilation) can result in POTS. Nuclear medicine studies can demonstrate delayed gastric transit times, raising the possibility of an autonomic neuropathy; however, an increased awareness of symptoms (hypervigilance) may also explain some of the concurrence of IBS and POTS. ${ }^{9}$ Serum tryptase taken immediately after an episode of flushing or a 24-hour urinary $N$-methylhistamine level may provide some evidence of mast cell activation; however, this is uncommon. ${ }^{5}$

Many patients go through a process of restricting their diet and/or food challenges for which standardized protocols may be used in an attempt to identify the triggers for symptoms of orthostatic intolerance. ${ }^{10}$ The benefit of a low fermentable oligo-, di- monosaccharides and polyoles diet is uncertain and a recent systematic review questioned the quality of evidence for this approach. ${ }^{11}$ Interestingly, the treatment of POTS may improve IBS symptoms, as seen in a cohort of children treated with fludrocortisone. ${ }^{12}$

\section{Hypermobility syndrome}

Concurrent hypermobility, often referred to as Ehlers Danlos Syndrome, is overrepresented in patients with POTS. ${ }^{13}$
The Beighton score is a standard tool used to document the presence of hypermobility. ${ }^{14}$ Since hypermobility may reflect a connective tissue matrix weakness, a reduction in venous return due to poor vascular wall integrity, evident on ultrasound when the vessels collapse under gentle pressure from the ultrasound probe, can sometimes be observed. However, a higher prevalence of small fiber neuropathy in the hypermobile group and normal arterial stiffness (measured in large vessels using tonometry) suggest vessel wall integrity is not the only reason for concurrent joint hypermobility and POTS. ${ }^{15}$ An association between anxiety, interoceptive sensibilities, chronic fatigue syndrome and either hypermobility or POTS has been reported by several groups. ${ }^{16-19}$

\section{Vascular compression syndromes}

Of interest to the vascular specialists (but of little relevance to most patients with POTS) is the association of vascular compression syndromes such as median arcuate ligament syndrome, thoracic outlet syndrome and pelvic compression syndrome with POTS, presumably due to the reduction in venous return that may occur with these conditions..$^{20-22}$ Turbulent flow or high peak systolic velocities in the superior mesenteric arteries may be identified during Doppler ultrasound, especially when provocative maneuvers such as standing (Figure 1A and B), expiration or Valsalva increase the angle of the superior mesenteric arteries or celiac axis. ${ }^{23,24}$ Median arcuate ligament syndrome is an uncommon condition in which patients develop postprandial or postexertional abdominal pain secondary to intermittent obstruction of celiac or superior mesenteric arteries by the median arcuate ligament, sometimes in association with celiac plexus compression (Figure 1C). ${ }^{25}$ Thoracic outlet syndrome describes the association of symptoms provoked by muscle, fascial or bony compression of vascular structures or nerve fibers at the thoracic outlet. Vessel flow characteristics during provocative maneuvers, such as elevation or abduction of the forearm, can be documented during ultrasound assessment (Figure 1D), although the false-positive rate can be significant. ${ }^{26}$ Increased cardiac sympathetic activity might relate to compression of the stellate ganglion or postganglionic efferent sympathetic fibers. ${ }^{20}$ While the peripheral and splanchnic vessels are most commonly implicated as the sites of venous pooling in POTS, pelvic vein varicosities may also result in significant venous pooling and can potentially be identified using transabdominal or transvaginal pelvic duplex ultrasound. Embolization or sclerotherapy can sometimes provide symptomatic relief. $^{27}$ 


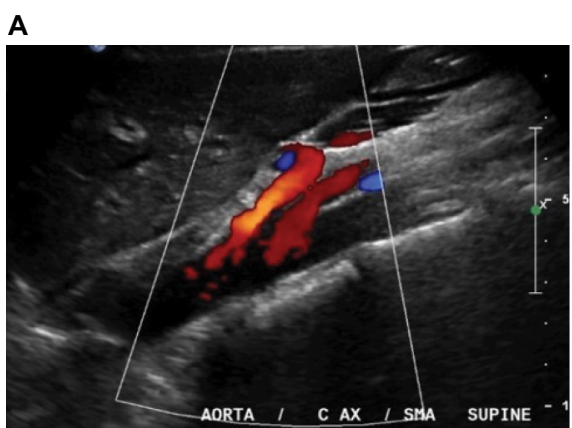

B

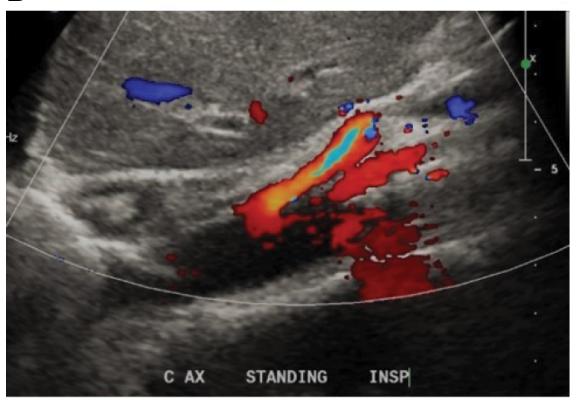

C

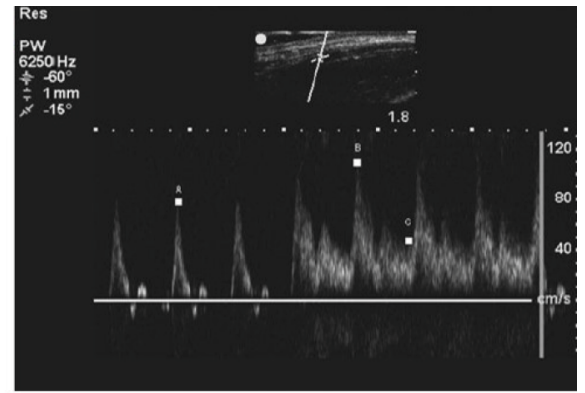

D

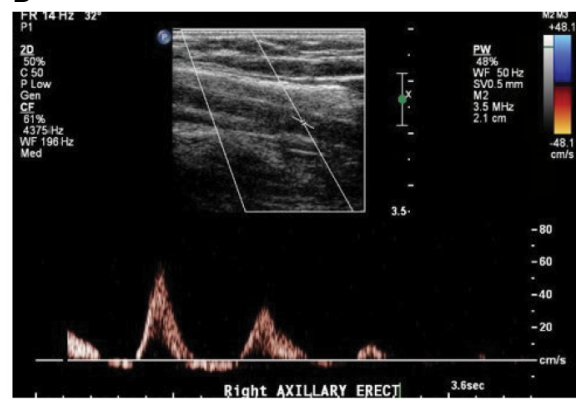

Figure I Pulse wave Doppler ultrasound in vascular compression syndrome.

Notes: Increase in Doppler intensity of the orange spectra and color reversal due to aliasing (blue region in the center of the vessel) indicates increase in blood flow velocity and turbulence in the compressed superior mesenteric artery of a patient upon change in posture from supine (A) to standing (B). In median arcuate ligament syndrome, the celiac artery may become compressed during expiration, resulting in increased blood flow velocity and turbulence seen here as an increase in height during systole and broadening waveform during diastole (C). In thoracic outlet syndrome, the blood flow waveform is completely lost in the axillary artery upon arm raising (D).

\section{Clinical approach toward POTS diagnosis}

The range of complex nonspecific symptoms experienced by patients with POTS can be a challenge. Careful history taking and clinical examination are, therefore, essential. Exhaustive investigations add little value to the overall management of this condition and should not be the routine as the costs are high with extremely low yield. Targeted investigations are necessary only when the index of suspicion is high for specific alternative diagnoses.

\section{Clinical history}

Individuals with POTS frequently present after a prolonged period of illness, and orthostatic intolerance has developed as a result of deconditioning, disrupted circadian rhythm or dietary deficiencies. The distinction between chronic fatigue syndrome, fibromyalgia and POTS is often blurred, with a significant overlap in symptomatology. Diagnostic criteria for POTS may be met in patients with chronic fatigue syndrome and fibromyalgia only on days when the fluid intake is lower or symptom burden is high. Use of a detailed medical questionnaire can potentially identify relevant symptoms and past medical history that patients may not volunteer. The circumstances surrounding symptom onset may provide useful information, with some patients developing symptoms following a period of rapid growth while others recall a traumatic or immunologic trigger such as vaccination or Epstein-Barr virus infection. In particular, associations between the development of POTS and recent receipt of the human papillomavirus vaccine have started to appear in the literature. ${ }^{28}$ Specific enquiry may also reveal concurrent conditions (Table 1) contributing to the symptoms and signs of POTS, including syncope, hypermobility, IBS or food intolerances, autonomic neuropathy and postural hypotension. Overactive "neurogenic" bladder can also be present in individuals with POTS.

Specific enquiries on the use of supplements, current and previous medications can help identify the medications that may exacerbate symptoms by reducing the intravascular volume (diuretics, mineralocorticoid receptor antagonists such as drospirenone), increasing vasodilation (calcium channel blockers, $\alpha$-antagonists) or increasing fatigue ( $\beta$-receptor antagonists) as well as clarifying the effect of historical interventions that might be under consideration. Clarifying the external factors that may contribute to symptomatology, such as daily salt and water intake, sleep hygiene and physical activity, as well as exploring the symptoms of anxiety and depression are also important. The presence of concentrated 
Table I Concurrent and exclusion diagnoses in patients with POTS and orthostatic intolerance

\begin{tabular}{|c|c|c|}
\hline Diagnosis & Relevant history & Relevant examination findings \\
\hline \multicolumn{3}{|c|}{ Concurrent diagnoses in POTS patients } \\
\hline Syncope & $\begin{array}{l}\text { Triggers and circumstances surrounding loss of } \\
\text { consciousness episodes }\end{array}$ & No specific examination findings \\
\hline Hypermobility & $\begin{array}{l}\text { Recurrent subluxation or dislocation of joints, bruising } \\
\text { tendency }\end{array}$ & $\begin{array}{l}\text { Assessment of hyperextension at metacarpophalangeal } \\
\text { joints, elbows, knees, hips and wrist flexion (Beighton } \\
\text { score) }\end{array}$ \\
\hline Irritable bowel syndrome & Frequent diarrhea, constipation and bloating & Abdominal tenderness and bloating \\
\hline Autonomic neuropathy & $\begin{array}{l}\text { COMPASS } 31 \text { questionnaire useful for an overview of } \\
\text { autonomic symptoms (Table } 2 \text { ) }\end{array}$ & $\begin{array}{l}\text { Lack of HR variability with deep breathing and significant } \\
\text { postural hypotension }\end{array}$ \\
\hline Postural hypotension & $\begin{array}{l}\text { Orthostatic symptoms often resolve when recumbent, } \\
\text { careful medication history }\end{array}$ & Lying and standing blood pressure and HR assessment \\
\hline \multicolumn{3}{|c|}{ Exclusion diagnoses for patients with orthostatic intolerance } \\
\hline Anemia or iron deficiency & $\begin{array}{l}\text { Blood loss (surgery, menorrhagia, malaena), reduced } \\
\text { red meat consumption }\end{array}$ & Pallor, pale conjunctivae \\
\hline Renal disease & Nausea, vomiting, fatigue, loss of appetite & $\begin{array}{l}\text { Peripheral edema, change in urinary pattern, treatment- } \\
\text { resistant hypertension }\end{array}$ \\
\hline Diabetes mellitus & Polydipsia, polyuria, fatigue & Ketotic breath, unintentional weight loss \\
\hline Diabetes insipidus & Polydipsia, polyuria & Signs of dehydration \\
\hline Thyroid disease & Abnormal HR when recumbent & Resting tachycardia, eyelid retraction, goiter \\
\hline Adrenal insufficiency & Prior steroid use & Skin hyperpigmentation \\
\hline Hypercortisolism & Steroid use & Striae, distribution of adipose tissue \\
\hline Malignancy & Prior malignancy, weight loss, fatigue & $\begin{array}{l}\text { Lymphadenopathy, breast lumps, palpable mass on digital } \\
\text { rectal examination }\end{array}$ \\
\hline Chronic infection & Febrile illness at the onset of symptoms & Fever \\
\hline Pulmonary embolism & $\begin{array}{l}\text { Chest pain, shortness of breath, recent immobility or } \\
\text { previous deep vein thrombosis }\end{array}$ & Pleural rub, supine tachycardia, lower limb swelling \\
\hline $\begin{array}{l}\text { Arrhythmias or cardiac } \\
\text { disease }\end{array}$ & $\begin{array}{l}\text { Palpitations (symptoms not exclusively related to } \\
\text { posture) }\end{array}$ & $\begin{array}{l}\text { Abnormal pulse quality or rhythm, presence of cardiac } \\
\text { murmurs }\end{array}$ \\
\hline Autoimmune disease & Fatigue, joint involvement & $\begin{array}{l}\text { Malar rash, inflamed joints, Holmes-Adie pupils in patients } \\
\text { with autoimmune autonomic ganglionopathy (very rare) }\end{array}$ \\
\hline
\end{tabular}

Abbreviations: HR, heart rate; POTS, postural tachycardia syndrome.

urine despite good oral fluid intake suggests insensible fluid and electrolyte loss and can be heightened by some physical activities such as hot yoga. The timing and number of hours spent sleeping may identify significant abnormalities in circadian rhythm or other sleep disorders. POTS may sometimes be accompanied by cholinergic symptoms (decreased saliva and tear production, delayed gastric transit associated with early satiety, nausea, constipation and bladder dysfunction) ${ }^{29}$ or associated with symptoms and signs of autoimmune conditions. ${ }^{30}$ Several validated questionnaires may be useful to explore the presence of autonomic features and track severity of symptoms in patients with POTS (Table 2).

\section{Clinical examination}

HR and blood pressure should be assessed while the patient is supine and then during a 10-minute period of standing (Figure 2). If postural HR abnormalities are evident, tilttable tests contribute little additional information. However, the timing and duration of the exaggerated HR response in patients with POTS has not been clearly defined, and the HR increment in an individual may demonstrate considerable daily variability. Therefore, if the patient reports typical postural symptoms but does not meet the criteria for POTS while standing in the clinic for 10 minutes, further investigation with tilt testing may still be warranted as the sensitivity of the bedside test is relatively low. ${ }^{31}$ General physical examination may identify rashes, Raynaud's phenomenon or acrocyanosis of dependent limbs as a result of venous pooling (Figure 3A and B). Auscultation for carotid, renal and epigastric bruits and cardiac murmurs should be undertaken. Other clinical assessments may focus on examining joint hypermobility (Figure 3C) and pupillary size and reaction to light and accommodation to detect evidence of cholinergic failure (Holmes-Adie pupil). Table 1 shows a list of conditions that may contribute to symptoms of orthostatic intolerance for due considerations when working up patients with possible POTS. 
Table 2 Adjunct questionnaires

\begin{tabular}{|c|c|c|c|}
\hline Questionnaire & Comments & Pros & Cons \\
\hline COMPASS $31^{86}$ & $\begin{array}{l}\text { Documents the presence of sudomotor, } \\
\text { vasomotor, gastrointestinal, genitourinary, } \\
\text { pupillomotor and orthostatic symptoms to } \\
\text { reflect the extent of autonomic dysfunction }\end{array}$ & $\begin{array}{l}\text { Provides an overview of symptoms } \\
\text { related to autonomic function in } \\
\text { terms of frequency and evolution }\end{array}$ & $\begin{array}{l}\text { Presence of irritable bowel syndrome } \\
\text { (which may not reflect autonomic } \\
\text { dysfunction) can significantly affect } \\
\text { the score }\end{array}$ \\
\hline Winker ${ }^{87}$ & $\begin{array}{l}\text { Validated for occupational health } \\
\text { assessments }\end{array}$ & $\begin{array}{l}\text { Evaluates the frequency of } 10 \\
\text { orthostatic-related symptoms }\end{array}$ & $\begin{array}{l}\text { Does not provide a measure for } \\
\text { symptom severity }\end{array}$ \\
\hline $\begin{array}{l}\text { Orthostatic } \\
\text { Hypotension }\end{array}$ & $\begin{array}{l}\text { Validated in subjects with orthostatic } \\
\text { hypotension and may be useful to evaluate }\end{array}$ & $\begin{array}{l}\text { Likert scale recording the severity of } \\
\text { six orthostatic symptoms (and ability }\end{array}$ & $\begin{array}{l}\text { Some uncertainties in scoring if } \\
\text { symptoms are severe but occur }\end{array}$ \\
\hline Questionnaire $^{88}$ & $\begin{array}{l}\text { acute changes during an orthostatic stress } \\
\text { test }\end{array}$ & $\begin{array}{l}\text { to stand or walk for short or long } \\
\text { periods) }\end{array}$ & infrequently \\
\hline $\begin{array}{l}\text { Short Form } 36 \\
(\mathrm{SF}-36)^{89}\end{array}$ & $\begin{array}{l}\text { Widely used, well-validated scale for quality } \\
\text { of life assessments }\end{array}$ & $\begin{array}{l}\text { Contains } 36 \text { questions addressing } \\
\text { social and functional domains } \\
\text { reflecting the quality of life over the } \\
\text { preceding } 4 \text { weeks }\end{array}$ & $\begin{array}{l}\text { Some uncertainties in scoring if } \\
\text { symptoms fluctuate or concurrent } \\
\text { illness occurred during the } 4 \text { weeks }\end{array}$ \\
\hline Beighton score ${ }^{14}$ & $\begin{array}{l}\text { I point for passive hyperextension of } \\
\text { each elbow, each knee and each fifth } \\
\text { metacarpophalangeal joint, as well as I point } \\
\text { for each wrist and I point for the ability to } \\
\text { place the palms on the floor while standing } \\
\text { with straight legs }\end{array}$ & Useful scores for joint hypermobility & $\begin{array}{l}\text { Does not discriminate between types } \\
\text { of Ehlers Danlos Syndrome as there is } \\
\text { no score for skin elasticity, bruising or } \\
\text { genetic abnormalities }\end{array}$ \\
\hline
\end{tabular}
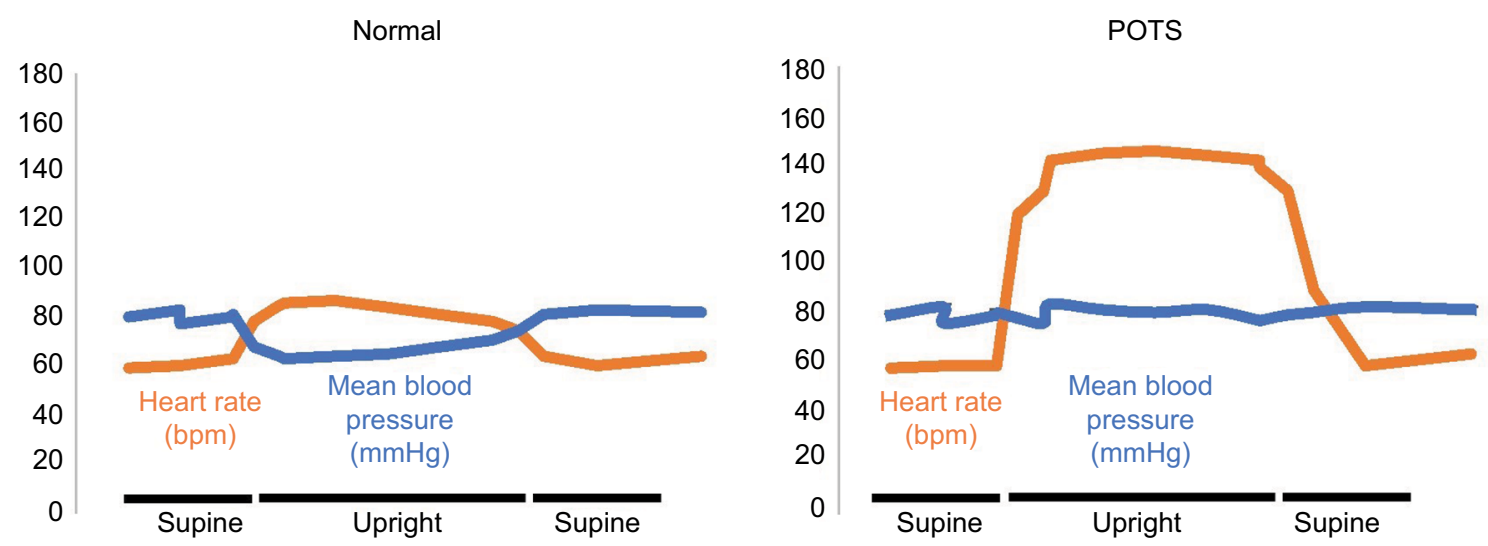

Figure 2 Supine and upright heart rate and blood pressure.

Notes: Supine and upright HR (orange) and blood pressure (blue) profiles of a normal subject (left panel) and a subject with POTS (right panel) demonstrating an exaggerated $\mathrm{HR}$ increase ( $>30 \mathrm{bpm}$ ) and relatively stable blood pressure.

Abbreviations: bpm, beats per minute; HR, heart rate; POTS, postural tachycardia syndrome.

\section{Investigations}

\section{Cardiovascular investigations}

An electrocardiogram and 24-hour monitoring of cardiac rhythm may identify conduction abnormalities or unexpected arrhythmias on rare occasions. More commonly, sinus tachycardia is seen to correlate with symptoms of orthostatic intolerance in POTS patients.

\section{Tilt-table test}

The head-up tilt-table test is the gold standard for diagnosis of orthostatic dysregulation and vasovagal syncope and may uncover even subtle physiologic changes, as the calf muscles contribute less to venous return when the patient is supported on a tilt table. Some centers adopt a provocation protocol using either sublingual nitrates or intravenous infusion of isoproterenol. ${ }^{32}$ However, interpreting a positive tilt test with provocation is complicated by the fact that syncope can be induced in individuals without POTS or orthostatic dysregulation with sufficient provocation. ${ }^{33}$ While positive response to acute intervention with intravenous fluids and midodrine has been demonstrated during a 5-minute tilt test, this has yet to be correlated with long-term response. ${ }^{34}$

\section{Autonomic testing}

To interpret autonomic function tests, it is important to have a basic understanding of the baroreceptor reflex. Baroreceptors 
A

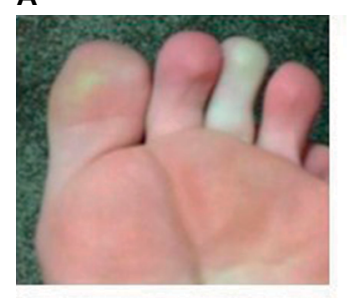

B

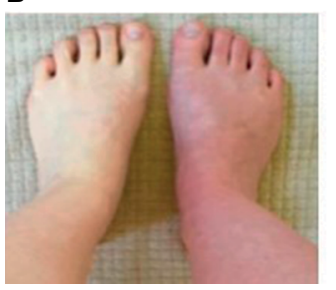

Figure 3 Common clinical signs.

Notes: (A) Raynaud's phenomenon; (B) acrocyanosis; (C) hypermobility demonstrating the ability to bring the thumb in contact with the ipsilateral forearm as part of the Beighton score (for additional information on Beighton scoring system, see Table 2). In (B) the right leg had been dependent whilst the left leg had remained on the bed for a few minutes revealing the color change seen with venous pooling. Images were kindly provided by patients along with their written informed consent to publish the images.

are stretch-sensitive mechanoreceptors located in the aortic arch and carotid sinuses. They monitor changes in blood pressure and provide a rapid negative feedback loop between $\mathrm{HR}$ and blood pressure. Elevated blood pressure activates the baroreflex, leading to decreases in HR and blood pressure. A drop in blood pressure will inhibit the baroreflex, leading to increases in HR and blood pressure. Baroreflex-induced changes in blood pressure are mediated by both branches of the autonomic nervous system: the parasympathetic and sympathetic systems. Rapid baroreflex adjustments are critical for regulation of HR and peripheral vascular resistance during orthostatic stress. ${ }^{35,36}$ In individuals with reduced venous return during orthostasis but an intact baroreflex, persistent reduction in stretch of the baroreceptors results in an exaggerated and sustained tachycardia. During deep inspiration and expiration while supine, however, individuals with POTS generally have a normal variation in HR variability (preserved vagal function) as the baroreflex responds to changes in intrathoracic pressure. Immediately following a Valsalva maneuver, however, the normal rebound in blood pressure (phase IV) is exaggerated, reflecting a vigorous pressor response. A reduced ability to buffer a fall in activation (stretch) of the baroreceptors may occur in a subgroup of "hyperadrenergic" POTS patients with high background sympathetic tone.

\section{Plasma and urine catecholamines}

Hyperadrenergic POTS may relate to an increase in production of norepinephrine ${ }^{37}$ or defective norepinephrine clear- ance..$^{38-42}$ The increment in norepinephrine after 10 minutes of head-up tilt versus supine rest has been used to dichotomize individuals with POTS into those with normal and those with hyperadrenergic responses. ${ }^{43}$ Theoretically, patients with higher norepinephrine levels during tilt are less likely to respond to $\alpha$-agonist therapy (e.g., midodrine). One small study has shown patients with neuropathic POTS had a better HR response to midodrine when compared with patients with hyperadrenergic POTS, however symptomatic response was not evaluated. ${ }^{44} \mathrm{~A}$ search for single-nucleotide polymorphisms in the $S L C 6 A 2$ gene encoding the norepinephrine transporter (NET) failed to demonstrate pathogenic variants in patients with POTS,,${ }^{45}$ but the expression of NET on the cell membrane is dependent on phosphorylation and glycosylation, indicating that other genes or epigenetic modification may contribute to hyperadrenergic POTS. ${ }^{46}$ Further, sympathetic denervation in neuropathic POTS could be expected to result in a decreased myocardial uptake of meta-iodobenzylguanidine, a noradrenaline analog readily taken up by sympathetic nerves via NET. ${ }^{47}$ However, there was no correlation between cardiac meta-iodobenzylguanidine uptake and sympathetic skin responses, catecholamine levels, symptom severity or other autonomic parameters in POTS patients. ${ }^{48}$

\section{Assessment of intravascular volume}

Theoretically, low angiotensin levels may exacerbate POTS, as angiotensin has both a direct vasoconstrictor effect and drives renal fluid and sodium reuptake by stimulating aldosterone release from the adrenals. Lower than expected levels of renin and angiotensin were demonstrated in a group of patients with POTS, despite lower blood volume measures than the control group, although the implications of this finding for treatment are unclear. ${ }^{49}$ Fludrocortisone, a synthetic aldosterone analog, is often used empirically to address the potential contribution of hypovolemia to orthostatic symptoms. In pediatric POTS patients with urinary sodium excretion $<124 \mathrm{mmol} / \mathrm{L}$ per 24 hours, pretreatment symptom burden was significantly higher while posttreatment response to oral rehydration salts was significantly greater. ${ }^{50}$ In practice, the assessment of intravascular volume and integrity of the renin-angiotensin system are rarely performed, with techniques to measure total blood volume (thermodilution, dye dilution, Technetium-99m or Chromium-51 labeled erythrocytes and Iodine-131 labeled albumin) typically reserved for research purposes only.

Evidence of venous pooling can be demonstrated using labeled erythrocytes in conjunction with a gamma counter, impedance plethysmography and strain gauge measures of calf diameter increment during venous occlusion and head- 
up tilt. ${ }^{51-53}$ Usually, individuals with POTS without excessive peripheral pooling have either hypovolemia (as demonstrated by indocyanine green dye dilution) or increased splanchnic blood flow despite peripheral vasoconstriction. ${ }^{53}$ Using Doppler ultrasound, an increase in superior mesenteric artery blood flow can be demonstrated in some patients with POTS. ${ }^{54}$ At present, the above tools are used primarily in research studies rather than to guide or assess response to therapy.

\section{Assessment of cerebral blood flow}

Brain fog is a common symptom in POTS. ${ }^{55}$ Doppler ultrasound has been used to measure cerebral blood flow velocity during postural maneuvers and cognitive tasks. Inability to buffer the cerebral circulation against peripheral circulation changes during orthostasis and excessive cerebral vascular constriction may be present, although these findings can be variable ${ }^{56,57}$ An increased oscillatory pattern of cerebral blood flow has been described in patients with POTS during head-up tilt that has been demonstrated to be associated with marked reduction in cognitive performance and functional hyperemia. ${ }^{58,59}$ Further, downregulation of nitric oxide receptor sites may explain the impaired nitric oxide-related cerebral vasodilation and blunted cerebral blood flow velocity following administration of sodium nitroprusside while supine and during upright tilt. ${ }^{60}$ Further studies are needed to evaluate the clinical utility of cerebral blood flow measurements in diagnosis and treatment of POTS.

\section{Immunologic workup}

There is uncertainty around the significance of autoantibodies in POTS. ${ }^{61}$ Sera from patients with POTS have produced exaggerated vascular constriction of a rat arteriole in vitro and an immunofluorescent assay identified autoantibodies binding to adrenergic receptors. ${ }^{3}$ However, these tests are confined to research use and not used in current clinical practice. Autoantibodies targeting the components of nicotinic receptors are generally associated with orthostatic hypotension rather than tachycardia, but low levels of these, and many other autoantibodies, have been detected in patients with POTS. ${ }^{29,62}$ At present, immunotherapy for POTS patients has been understudied and, in general, the risks are considered to outweigh the uncertain benefits. In contrast, immunotherapy has been successful in the treatment of generalized autonomic dysfunction associated with cholinergic autoantibodies such as in ganglionopathy. ${ }^{63}$ Skin prick testing is sometimes undertaken to identify potential triggers to IgE-mediated mast cell histamine release. Urinary methylhistamine or serum tryptase levels performed on specimens taken during an episode of flushing and tachycardia may also provide some evidence of mast cell involvement. However, false-positive and -negative results may occur and ultimately, responses to food elimination diets and food challenges may provide the most clinically relevant information.

\section{Approach to therapy for patients with POTS}

The first consideration in managing POTS is patient education concerning pathophysiology and symptoms, with numerous simple lifestyle strategies aimed to reduce the burden of POTS-related symptoms. Table 3 provides a summary of the approach to treating POTS patients based on their dominant symptoms.

\section{Nonpharmacologic interventions}

Receiving an explanation for the physiologic basis underlying POTS can be very reassuring for patients. Furthermore, strategies to avoid triggers and manage symptoms are more likely to be adopted if patients understand the underlying

Table 3 Choice of therapy based on phenotype

\begin{tabular}{|c|c|c|}
\hline Symptoms or signs & Rationale & Therapy \\
\hline All patients & $\begin{array}{l}\text { Avoidance of external factors } \\
\text { contributing to orthostatic- } \\
\text { related symptoms }\end{array}$ & $\begin{array}{l}\text { Avoid overheating, elevate head of bed, lifestyle management including diet, } \\
\text { sleep hygiene and a recumbent exercise program }{ }^{65} \\
\text { Use of physical counter maneuvers and tonic muscle contraction to combat } \\
\text { pre-syncopal symptoms }\end{array}$ \\
\hline $\begin{array}{l}\text { White/cold peripheries and } \\
\text { narrow upright pulse pressure } \\
\text { (systolic-diastolic BP) }\end{array}$ & Suggestive of low blood volume & Increase oral salt and water intake and consider adding fludrocortisone \\
\hline $\begin{array}{l}\text { Acrocyanosis of dependent } \\
\text { peripheries }\end{array}$ & Possible venous pooling & $\begin{array}{l}\text { Use of compression garments when upright }{ }^{51} \text { and consider adding vasopressor } \\
\text { therapy (e.g., midodrine) }\end{array}$ \\
\hline Supine heart rate $>90 /$ minute & $\begin{array}{l}\text { Increased circulating } \\
\text { noradrenaline }\end{array}$ & $\begin{array}{l}\text { Confirm normal thyroid function tests, anxiety management, rate control with } \\
\text { low dose } \beta 2 \text { antagonists (propranolol) or Ivabradine }\end{array}$ \\
\hline Concurrent IBS & Splanchnic pooling & Consider referral to a dietician and/or trial of an elimination diet \\
\hline
\end{tabular}

Abbreviations: BP, blood pressure; IBS, irritable bowel syndrome. 
rationale. Nonpharmacologic strategies include avoidance of exposures that may contribute to overheating, improving venous return by activation of calf muscles and tonic muscle contraction when lightheaded. Maintaining good hydration may include supplementing salt and water intake and withdrawal of medications that interfere with fluid balance (drospirenone, diuretics). Where food intolerances are problematic with suspected splanchnic pooling, providing dietary advice and referral to a dietician may be of benefit. The use of full-length pressure stockings can be of considerable benefit in reducing POTS symptoms. Previously, it has been demonstrated that a $45-50 \mathrm{mmHg}$ inflatable pressure suit significantly reduced abnormal HR and blood pressure responses when patients with orthostatic intolerance were upright. ${ }^{51}$ However, difficulty in applying compression garments and reduced user compliance during warmer weather (when they are likely to be of greatest benefit) limit the translation of potential benefits from external compression into significant benefit in many patients.

In patients with autonomic failure, sleeping in a seated position can reduce loss of salt and water at night. ${ }^{64}$ It has been postulated that increased renin secretion and consequent aldosterone increase can occur with reduced renal arterial pressure when a patient sleeps with the head of the bed raised by $\sim 10 \mathrm{~cm}$. Further, a graduated exercise program incorporating recumbent exercises may also be beneficial in POTS. ${ }^{65}$ Short-term exercise training has been shown to increase the baroreflex sensitivity in POTS patients and decrease the upright HR. ${ }^{66}$ It is important to keep a modest expectation of activity levels in the early phase to avoid postexertional fatigue and abandonment of the program, as a gradual increase in exercise can result in significant improvement in both symptoms and orthostatic HR in patients with POTS. ${ }^{65,67,68}$ Other lifestyle factors include adoption of good sleep hygiene to address disrupted circadian rhythm, and psychologic support, to encourage realistic expectations of integration back into the study or workplace.

\section{Pharmacologic interventions}

A recent consensus statement has highlighted a lack of quality evidence for the use of pharmacotherapy in POTS. ${ }^{69}$ Empirical trials of medications are generally adopted based on the clinician's impression of the POTS phenotype (Table 3). In practice, single or combination therapies directed at increasing intravascular volume, increasing peripheral vasoconstriction and controlling HR are often employed. Fludrocortisone is a reasonable option for increasing the intravascular volume, while midodrine is useful in those with peripheral pooling.
Specifically, midodrine was superior to placebo in the subgroup of patients with peripheral venous pooling (as indicated by an increase in calf diameter during venous occlusion or tilt), whereas in patients without peripheral pooling, the HR change with midodrine was not significantly different from placebo. ${ }^{44}$ Nonselective $\beta 2$ antagonists such as low-dose propranolol may be effective for treating the elevated HR. ${ }^{70}$ These are preferred over the cardio-selective ones, given the added potential for reducing pathogenic peripheral or splanchnic vasodilation. One major limiting factor in the use of $\beta 2$ antagonist is the potential for worsening chronic fatigue symptoms that are often present in POTS patients. Ivabradine is an alternative agent to $\beta 2$ antagonists that has been shown to be of benefit in recent studies. ${ }^{71}$ Rescue therapy with intravenous saline during acute decompensation can be helpful, and intermittent infusions can sometimes be considered in highly symptomatic patients in whom standard therapy has failed. ${ }^{72}$

\section{Miscellaneous interventions}

Several other POTS interventions have been reported in case series. In specialized centers, patients with significant postprandial tachycardia are occasionally treated with octreotide, a somatostatin analog, used to reduce splanchnic pooling. ${ }^{73,74}$ However, the need for subcutaneous or intramuscular administration, as well as the cost and side effect profile of octreotide have limited its use. A small case series on sinus node modification has found no significant benefits. ${ }^{75}$ There is minimal information on the effect of immunomodulatory therapies, despite data suggesting a correlation between immune dysregulation and POTS. ${ }^{30}$ Good response to intravenous immunoglobulin has been described in two patients with POTS in association with antiphospholipid syndrome. ${ }^{76}$ Several miscellaneous therapies have been reported in POTS patients, but these remain investigational: erythropoietin, modafinil, methylphenidate and pyridostigmine. ${ }^{77-80}$ The predominance of POTS in young females could reflect an interaction between female hormones and mineralocorticoid receptors; however, the effect of manipulating female hormones requires further study. Oral contraceptives containing drosperinone are best avoided, given they are antagonists at the mineralocorticoid receptors. ${ }^{81}$ A trial of histamine- 1 and -2 antagonists may also be considered where allergy seems to be a contributing factor.

\section{Prognosis}

While there is no evidence for increased mortality associated with POTS, significant morbidities may persist. The 
prognosis of this condition is difficult to ascertain due to the heterogeneity and our incomplete understanding of the underlying pathology. Nevertheless, insights on the prognosis can be gained from the reports from several centers. A prospective, longitudinal study of 56 patients who were treated at the Mayo clinic with a combination of nonpharmacologic interventions and $\beta$-blockers (54\%), fludrocortisone (24\%) or midodrine (17\%) found improvement in $70 \%$ of patients, while $30 \%$ became worse after 1 year of treatment. ${ }^{82} \mathrm{~A}$ retrospective review of POTS patients from the same clinic showed symptomatic improvement in up to $80 \%$, although only $33 \%$ were managing recreational activities 5 years after diagnosis and $73 \%$ were still requiring treatments. ${ }^{83}$ Questionnaires returned by 172 of 502 patients from another retrospective study indicated symptom resolution in $19 \%$, improvement in $51 \%$ and unchanged or worsened symptoms in $12 \%$ of POTS patients at 5 years. ${ }^{84}$ Thirty-one percent of patients responding to a phone questionnaire reported being asymptomatic $\sim 10$ years after their first consult. ${ }^{85}$ Taken together, the majority of POTS patients may experience improvements in their symptom severity, while symptom progression and complete recovery are evident only in a minority.

\section{Conclusion}

The mechanisms underlying POTS are complex and remain poorly understood. The diagnosis is mainly based on clinical history and determination of blood pressure and HR responses in the upright posture. Targeted investigations focusing on autonomic function, assessment of intravascular volume and immunologic workup may help to identify factors contributing to the symptom complex in a subset of patients. Current available therapies for this condition are mainly focused on symptom control. Further research is needed to help clarify the optimal approach to diagnosis, evaluate novel therapeutics and inform long-term prognosis of this debilitating condition.

\section{Disclosure}

The authors report no conflicts of interest in this work.

\section{References}

1. Garland EM, Celedonio JE, Raj SR. Postural tachycardia syndrome: beyond orthostatic intolerance. Curr Neurol Neurosci Rep. 2015;15(9):60.

2. Grubb BP, Kosinski DJ, Boehm K, Kip K. The postural orthostatic tachycardia syndrome: a neurocardiogenic variant identified during head-up tilt table testing. Pacing Clin Electrophysiol. 1997;20(9 Pt 1):2205-2212.

3. Li H, Yu X, Liles C, et al. Autoimmune basis for postural tachycardia syndrome. J Am Heart Assoc. 2014;3(1):e000755.
4. Wang XL, Chai Q, Charlesworth MC, et al. Autoimmunoreactive IgGs from patients with postural orthostatic tachycardia syndrome. Proteomics Clin Appl. 2012;6(11-12):615-625.

5. Shibao C, Arzubiaga C, Roberts LJ 2nd, et al. Hyperadrenergic postural tachycardia syndrome in mast cell activation disorders. Hypertension. 2005;45(3):385-390.

6. Lau DH, Mahajan R, Lee G, Kalman JM, Sanders P. Towards improved care of postural tachycardia syndrome, inappropriate sinus tachycardia and vasovagal syncope patients: a call to action in Australia. Heart Lung Circ. 2016;25(1):8-11.

7. Mathias CJ, Low DA, Iodice V, Owens AP, Kirbis M, Grahame R. Postural tachycardia syndrome-current experience and concepts. Nat Rev Neurol. 2011;8(1):22-34.

8. Stewart JM, Montgomery LD. Regional blood volume and peripheral blood flow in postural tachycardia syndrome. Am J Physiol Heart Circ Physiol. 2004;287(3):H1319-H1327.

9. Benarroch EE. Postural tachycardia syndrome: a heterogeneous and multifactorial disorder. Mayo Clin Proc. 2012;87(12):1214-1225.

10. Sampson HA, Gerth van Wijk R, Bindslev-Jensen C, et al. Standardizing double-blind, placebo-controlled oral food challenges: American Academy of Allergy, Asthma \& Immunology-European Academy of Allergy and Clinical Immunology PRACTALL consensus report. J Allergy Clin Immunol. 2012;130(6):1260-1274.

11. Krogsgaard LR, Lyngesen M, Bytzer P. Systematic review: quality of trials on the symptomatic effects of the low FODMAP diet for irritable bowel syndrome. Aliment Pharmacol Ther. 2017;45(12):1506-1513.

12. Fortunato JE, Wagoner AL, Harbinson RL, D’Agostino RB Jr, Shaltout HA, Diz DI. Effect of fludrocortisone acetate on chronic unexplained nausea and abdominal pain in children with orthostatic intolerance. J Pediatr Gastroenterol Nutr. 2014;59(1):39-43.

13. De Wandele I, Rombaut L, Leybaert L, et al. Dysautonomia and its underlying mechanisms in the hypermobility type of Ehlers-Danlos syndrome. Semin Arthritis Rheum. 2014;44(1):93-100.

14. Beighton P, Solomon L, Soskolne CL. Articular mobility in an African population. Ann Rheum Dis. 1973;32(5):413-418.

15. Cheng JL, Au JS, Guzman JC, Morillo CA, MacDonald MJ. Cardiovascular profile in postural orthostatic tachycardia syndrome and EhlersDanlos syndrome type III. Clin Auton Res. 2017;27(2):113-116.

16. Smith TO, Easton V, Bacon H, et al. The relationship between benign joint hypermobility syndrome and psychological distress: a systematic review and meta-analysis. Rheumatology (Oxford). 2014;53(1):114-122.

17. Bulbena A, Baeza-Velasco C, Bulbena-Cabre A, et al. Psychiatric and psychological aspects in the Ehlers-Danlos syndromes. Am J Med Genet C Semin Med Genet. 2017;175(1):237-245.

18. Bulbena A, Gago J, Pailhez G, Sperry L, Fullana MA, Vilarroya O. Joint hypermobility syndrome is a risk factor trait for anxiety disorders: a 15-year follow-up cohort study. Gen Hosp Psychiatry. 2011;33(4): 363-370.

19. Garcia-Campayo J, Asso E, Alda M. Joint hypermobility and anxiety: the state of the art. Curr Psychiatry Rep. 2011;13(1):18-25.

20. Kaymak B, Ozcakar L, Oguz AK, Arsava M, Ozdol C. A novel finding in thoracic outlet syndrome: tachycardia. Joint Bone Spine. 2004;71(5): $430-432$.

21. Ozcakar L, Ertan H, Kaymak B. Two cases and two particular signs of thoracic outlet syndrome: tremor and tachycardia. Rheumatol Int. 2008;29(2):227-228.

22. Petrosyan M, Franklin A, Guzzetta P, Abdullah H, Kane TD. Experience and Results for Laparoscopic Median Arcuate Ligament Release in Young Patients With Postural Orthostatic Tachycardia Syndrome. Gastroenterology.148(4):S1116.

23. Ozel A, Toksoy G, Ozdogan O, Mahmutoglu AS, Karpat Z. Ultrasonographic diagnosis of median arcuate ligament syndrome: a report of two cases. Med Ultrason. 2012;14(2):154-157.

24. Tembey RA, Bajaj AS, Wagle PK, Ansari AS. Real-time ultrasound: Key factor in identifying celiac artery compression syndrome. Indian J Radiol Imaging. 2015;25(2):202-205. 
25. van Petersen AS, Kolkman JJ, Gerrits DG, van der Palen J, Zeebregts CJ, Geelkerken RH; Dutch Mesenteric Ischemia Study Group. Clinical significance of mesenteric arterial collateral circulation in patients with celiac artery compression syndrome. J Vasc Surg. 2017;65(5): 1366-1374.

26. Nord KM, Kapoor P, Fisher J, et al. False positive rate of thoracic outlet syndrome diagnostic maneuvers. Electromyogr Clin Neurophysiol. 2008;48(2):67-74.

27. Daniels JP, Champaneria R, Shah L, Gupta JK, Birch J, Moss JG. Effectiveness of embolization or sclerotherapy of pelvic veins for reducing chronic pelvic pain: a systematic review. JVasc Interv Radiol. 2016;27(10):1478-1486.e8

28. Butts BN, Fischer PR, Mack KJ. Human papillomavirus vaccine and postural orthostatic tachycardia syndrome: a review of current literature. J Child Neurol. 2017;32(11):956-965.

29. Vernino S, Low PA, Fealey RD, Stewart JD, Farrugia G, Lennon VA. Autoantibodies to ganglionic acetylcholine receptors in autoimmune autonomic neuropathies. N Engl J Med. 2000;343(12):847-855.

30. Adamec I, Bach I, Barusic AK, Mismas A, Habek M. Assessment of prevalence and pathological response to orthostatic provocation in patients with multiple sclerosis. J Neurol Sci. 2013;324(1-2):80-83.

31. Winker R, Prager W, Haider A, Salameh B, Rudiger HW. Schellong test in orthostatic dysregulation: a comparison with tilt-table testing. Wien Klin Wochenschr. 2005;117(1-2):36-41.

32. Swissa M, Epstein M, Paz O, Shimoni S, Caspi A. Head-up tilt table testing in syncope: safety and efficiency of isosorbide versus isoproterenol in pediatric population. Am Heart J. 2008;156(3):477-482.

33. Macedo PG, Asirvatham SJ, Maia L, et al. Comparison of a shortened isosorbide dinitrate-potentiated head-up tilt testing with the conventional protocol: tolerance and diagnostic accuracy. Pacing Clin Electrophysiol. 2012;35(8):1005-1011.

34. Gordon VM, Opfer-Gehrking TL, Novak V, Low PA. Hemodynamic and symptomatic effects of acute interventions on tilt in patients with postural tachycardia syndrome. Clin Auton Res. 2000;10(1):29-33.

35. Thomson HL, Wright K, Frenneaux M. Baroreflex sensitivity in patients with vasovagal syncope. Circulation. 1997;95(2):395-400.

36. Chaddha A, Wenzke KE, Brignole M, et al. The role of the baroreflex in tilt table testing. JACC: Clinical Electrophysiology. 2016;2:812-817.

37. Goldstein DS, Holmes C, Frank SM, et al. Cardiac sympathetic dysautonomia in chronic orthostatic intolerance syndromes. Circulation. 2002;106(18):2358-2365.

38. Lambert E, Eikelis N, Esler M, et al. Altered sympathetic nervous reactivity and norepinephrine transporter expression in patients with postural tachycardia syndrome. Circ Arrhythm Electrophysiol. 2008;1(2):103-109.

39. Khan AW, Corcoran SJ, Esler M, El-Osta A. Epigenomic changes associated with impaired norepinephrine transporter function in postural tachycardia syndrome. Neurosci Biobehav Rev. 2017;74(Pt B):342-355.

40. Esler M, Jennings G, Lambert G, Meredith I, Horne M, Eisenhofer G. Overflow of catecholamine neurotransmitters to the circulation: source, fate, and functions. Physiol Rev. 1990;70(4):963-985.

41. Goldstein DS, Brush JE Jr, Eisenhofer G, Stull R, Esler M. In vivo measurement of neuronal uptake of norepinephrine in the human heart. Circulation. 1988;78(1):41-48.

42. Jacob G, Shannon JR, Costa F, et al. Abnormal norepinephrine clearance and adrenergic receptor sensitivity in idiopathic orthostatic intolerance. Circulation. 1999;99(13):1706-1712.

43. Crnosija L, Krbot Skoric M, Lovric M, et al. Differences in neurohumoral and hemodynamic response to prolonged head-up tilt between patients with high and normal standing norepinephrine forms of postural orthostatic tachycardia syndrome. Auton Neurosci. 2017;205:110-114.

44. Ross AJ, Ocon AJ, Medow MS, Stewart JM. A double-blind placebocontrolled cross-over study of the vascular effects of midodrine in neuropathic compared with hyperadrenergic postural tachycardia syndrome. Clin Sci (Lond). 2014;126(4):289-296.
45. Bayles R, Harikrishnan KN, Lambert E, et al. Epigenetic modification of the norepinephrine transporter gene in postural tachycardia syndrome. Arterioscler Thromb Vasc Biol. 2012;32(8):1910-1916.

46. Jayanthi LD, Annamalai B, Samuvel DJ, Gether U, Ramamoorthy S. Phosphorylation of the norepinephrine transporter at threonine 258 and serine 259 is linked to protein kinase C-mediated transporter internalization. J Biol Chem. 2006;281(33):23326-23340.

47. Vaidyanathan G. Meta-iodobenzylguanidine and analogues: chemistry and biology. Q J Nucl Med Mol Imaging. 2008;52(4):351-368.

48. Haensch CA, Lerch H, Schlemmer H, Jigalin A, Isenmann S. Cardiac neurotransmission imaging with 123I-meta-iodobenzylguanidine in postural tachycardia syndrome. J Neurol Neurosurg Psychiatry. 2010;81(3): 339-343.

49. Raj SR, Biaggioni I, Yamhure PC, et al. Renin-aldosterone paradox and perturbed blood volume regulation underlying postural tachycardia syndrome. Circulation. 2005;111(13):1574-1582.

50. Li J, Zhang Q, Liao Y, Zhang C, Du J. [Clinical value of 24-hour urinary sodium determination in children with postural tachycardia syndrome]. Zhonghua Er Ke Za Zhi. 2015;53(3):203-207. Chinese.

51. Streeten DH, Anderson GH Jr, Richardson R, Thomas FD. Abnormal orthostatic changes in blood pressure and heart rate in subjects with intact sympathetic nervous function: evidence for excessive venous pooling. J Lab Clin Med. 1988;111(3):326-335.

52. Stewart JM, Medow MS, Glover JL, Montgomery LD. Persistent splanchnic hyperemia during upright tilt in postural tachycardia syndrome. Am J Physiol Heart Circ Physiol. 2006;290(2):H665-H673.

53. Stewart JM, Weldon A. The relation between lower limb pooling and blood flow during orthostasis in the postural orthostatic tachycardia syndrome of adolescents. J Pediatr. 2001;138(4):512-519.

54. Tani H, Singer W, McPhee BR, et al. Splanchnic-mesenteric capacitance bed in the postural tachycardia syndrome (POTS). Auton Neurosci. 2000;86(1-2):107-113.

55. Ross AJ, Medow MS, Rowe PC, Stewart JM. What is brain fog? An evaluation of the symptom in postural tachycardia syndrome. Clin Auton Res. 2013;23(6):305-311.

56. Low PA, Novak V, Spies JM, Novak P, Petty GW. Cerebrovascular regulation in the postural orthostatic tachycardia syndrome (POTS). Am J Med Sci. 1999;317(2):124-133.

57. Schondorf R, Benoit J, Stein R. Cerebral autoregulation is preserved in postural tachycardia syndrome. J Appl Physiol (1985). 2005;99(3):828-835.

58. Ocon AJ, Medow MS, Taneja I, Clarke D, Stewart JM. Decreased upright cerebral blood flow and cerebral autoregulation in normocapnic postural tachycardia syndrome. Am J Physiol Heart Circ Physiol. 2009;297(2):H664-H673.

59. Stewart JM, Del Pozzi AT, Pandey A, Messer ZR, Terilli C, Medow MS. Oscillatory cerebral blood flow is associated with impaired neurocognition and functional hyperemia in postural tachycardia syndrome during graded tilt. Hypertension. 2015;65(3):636-643.

60. Del Pozzi AT, Pandey A, Medow MS, Messer ZR, Stewart JM. Blunted cerebral blood flow velocity in response to a nitric oxide donor in postural tachycardia syndrome. Am J Physiol Heart Circ Physiol. 2014;307(3): H397-H404.

61. Wells R, Tonkin A. Clinical approach to autonomic dysfunction. Intern Med J. 2016;46(10):1134-1139.

62. Wang XL, Ling TY, Charlesworth MC, et al. Autoimmunoreactive IgGs against cardiac lipid raft-associated proteins in patients with postural orthostatic tachycardia syndrome. Transl Res. 2013;162(1):34-44.

63. Iodice V, Kimpinski K, Vernino S, Sandroni P, Fealey RD, Low PA. Efficacy of immunotherapy in seropositive and seronegative putative autoimmune autonomic ganglionopathy. Neurology. 2009;72(23): 2002-2008.

64. Bannister R, Sever P, Gross M. Cardiovascular reflexes and biochemical responses in progressive autonomic failure. Brain. 1977;100(2):327-344. 
65. Fu Q, Vangundy TB, Galbreath MM, et al. Cardiac origins of the postural orthostatic tachycardia syndrome. J Am Coll Cardiol. 2010;55(25):2858-2868.

66. Galbreath MM, Shibata S, VanGundy TB, et al. Effects of exercise training on arterial-cardiac baroreflex function in POTS. Clin Auton Res. 2011;21(2):73-80.

67. Winker R, Barth A, Bidmon D, et al. Endurance exercise training in orthostatic intolerance: a randomized, controlled trial. Hypertension. 2005;45(3):391-398.

68. Fu Q, Levine BD. Exercise in the postural orthostatic tachycardia syndrome. Auton Neurosci. 2015;188:86-89.

69. Sheldon RS, Grubb BP, 2nd, Olshansky B, et al. 2015 heart rhythm society expert consensus statement on the diagnosis and treatment of postural tachycardia syndrome, inappropriate sinus tachycardia, and vasovagal syncope. Heart Rhythm. 2015;12(6):e41-e63.

70. Raj SR, Black BK, Biaggioni I, et al. Propranolol decreases tachycardia and improves symptoms in the postural tachycardia syndrome: less is more. Circulation. 2009;120(9):725-734.

71. McDonald C, Frith J, Newton JL. Single centre experience of ivabradine in postural orthostatic tachycardia syndrome. Europace. 2011;13(3):427-430.

72. Ruzieh M, Baugh A, Dasa O, et al. Effects of intermittent intravenous saline infusions in patients with medication-refractory postural tachycardia syndrome. J Interv Card Electrophysiol. 2017;48(3) 255-260.

73. Kanjwal K, Saeed B, Karabin B, Kanjwal Y, Grubb BP. Use of octreotide in the treatment of refractory orthostatic intolerance. Am J Ther. 2012;19(1):7-10.

74. Khan M, Ouyang J, Perkins K, Somauroo J, Joseph F. Treatment of refractory postural tachycardia syndrome with subcutaneous octreotide delivered using an insulin pump. Case Rep Med. 2015;2015: 545029 .

75. Shen WK, Low PA, Jahangir A, et al. Is sinus node modification appropriate for inappropriate sinus tachycardia with features of postural orthostatic tachycardia syndrome? Pacing Clin Electrophysiol. 2001;24(2):217-230.

76. Schofield JR, Blitshteyn S, Shoenfeld Y, Hughes GR. Postural tachycardia syndrome (POTS) and other autonomic disorders in antiphospholipid (Hughes) syndrome (APS). Lupus. 2014;23(7):697-702.
77. Kanjwal K, Saeed B, Karabin B, Kanjwal Y, Sheikh M, Grubb BP. Erythropoietin in the treatment of postural orthostatic tachycardia syndrome. Am J Ther. 2012;19(2):92-95.

78. Kanjwal K, Saeed B, Karabin B, Kanjwal Y, Grubb BP. Preliminary observations suggesting that treatment with modafinil improves fatigue in patients with orthostatic intolerance. Am JTher. 2011;18(6):449-452.

79. Kanjwal K, Saeed B, Karabin B, Kanjwal Y, Grubb BP. Use of methylphenidate in the treatment of patients suffering from refractory postural tachycardia syndrome. Am J Ther. 2012;19(1):2-6.

80. Kanjwal K, Karabin B, Sheikh M, et al. Pyridostigmine in the treatment of postural orthostatic tachycardia: a single-center experience. Pacing Clin Electrophysiol. 2011;34(6):750-755.

81. Vitale C, Mammi C, Gambacciani M, et al. Effect of hormone replacement therapy with the anti-mineralocorticoid progestin Drospirenone compared to tibolone on endothelial function and central haemodynamics in post-menopausal women. Int J Cardiol. 2017;227:217-221.

82. Kimpinski K, Figueroa JJ, Singer W, et al. A prospective, 1-year follow-up study of postural tachycardia syndrome. Mayo Clin Proc. 2012;87(8):746-752.

83. Sandroni P, Opfer-Gehrking TL, McPhee BR, Low PA. Postural tachycardia syndrome: clinical features and follow-up study. Mayo Clin Proc. 1999;74(11):1106-1110.

84. Bhatia R, Kizilbash SJ, Ahrens SP, et al. Outcomes of Adolescent-Onset Postural Orthostatic Tachycardia Syndrome. J Pediatr. 2016;173:149-153.

85. Sousa A, Lebreiro A, Freitas J, Maciel MJ. Long-term follow-up of patients with postural tachycardia syndrome. Clin Auton Res. 2012;22(3): $151-153$.

86. Sletten DM, Suarez GA, Low PA, Mandrekar J, Singer W. COMPASS 31: a refined and abbreviated Composite Autonomic Symptom Score. Mayo Clin Proc. 2012;87(12):1196-1201.

87. Winker R, Barth A, Dorner W, et al. Diagnostic management of orthostatic intolerance in the workplace. Int Arch Occup Environ Health. 2003;76(2):143-150.

88. Kaufmann H, Malamut R, Norcliffe-Kaufmann L, Rosa K, Freeman R. The Orthostatic Hypotension Questionnaire (OHQ): validation of a novel symptom assessment scale. Clin Auton Res. 2012;22(2):79-90.

89. Ware JE Jr, Sherbourne CD. The MOS 36-item short-form health survey (SF-36). I. Conceptual framework and item selection. Med Care. 1992;30(6):473-483.
Vascular Health and Risk Management

\section{Publish your work in this journal}

Vascular Health and Risk Management is an international, peerreviewed journal of therapeutics and risk management, focusing on concise rapid reporting of clinical studies on the processes involved in the maintenance of vascular health; the monitoring, prevention and treatment of vascular disease and its sequelae; and the involvement of

\section{Dovepress}

metabolic disorders, particularly diabetes. This journal is indexed on PubMed Central and MedLine. The manuscript management system is completely online and includes a very quick and fair peer-review system, which is all easy to use. Visit http://www.dovepress.com/ testimonials.php to read real quotes from published authors. 